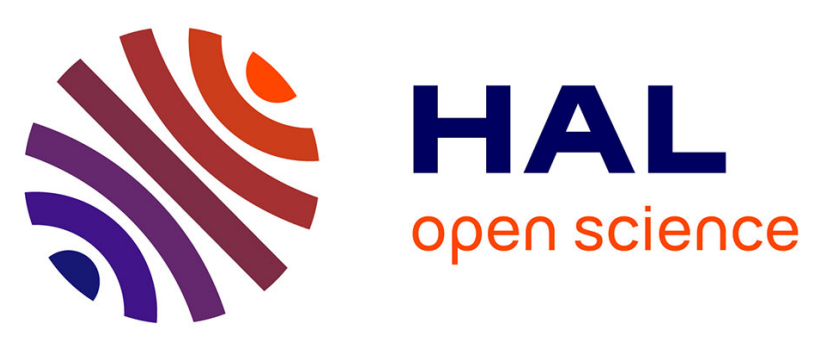

\title{
Students' Motivational Profiles and Achievement Outcomes in Physical Education: A Self-Determination Perspective
}

Julie Boiché, Philippe Sarrazin, Frederic M.E. Grouzet, Luc Pelletier, Julien Chanal

\section{To cite this version:}

Julie Boiché, Philippe Sarrazin, Frederic M.E. Grouzet, Luc Pelletier, Julien Chanal. Students' Motivational Profiles and Achievement Outcomes in Physical Education: A Self-Determination Perspective. Journal of Educational Psychology, 2008, 100, pp.688-701. hal-00389858

\section{HAL Id: hal-00389858 https://hal.science/hal-00389858}

Submitted on 29 May 2009

HAL is a multi-disciplinary open access archive for the deposit and dissemination of scientific research documents, whether they are published or not. The documents may come from teaching and research institutions in France or abroad, or from public or private research centers.
L'archive ouverte pluridisciplinaire HAL, est destinée au dépôt et à la diffusion de documents scientifiques de niveau recherche, publiés ou non, émanant des établissements d'enseignement et de recherche français ou étrangers, des laboratoires publics ou privés. 
Running Head: STUDENTS' MOTIVATIONAL PROFILES AND ACHIEVEMENT

Students' Motivational Profiles and Achievement Outcomes in Physical Education: A Self-

Determination Perspective

Julie C. S. Boiché \& Philippe G. Sarrazin

University of Grenoble, France

Frederick M. E. Grouzet

University of Victoria, Canada

Luc G. Pelletier

University of Ottawa, Canada

Julien P. Chanal

University of Grenoble, France

Journal of Educational Psychology (2008), 100, 688-701

Submitted: March 9, 2006

Revision received: December 6, 2006

Accepted: July 5, 2007

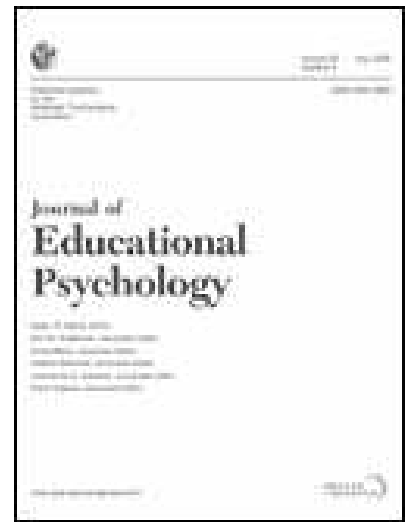

Acknowledgements: We would like to thank Aïna Chalabaev and Damien Tessier for their help in collecting the data, and Robert Brustad for his thorough reading of the manuscript.

Correspondence concerning this article should be addressed to Philippe Sarrazin, Laboratoire Sport et Environnement Social, Université Joseph Fourier - UFRAPS, BP53, 38041 Grenoble cedex 9, France. +33 475.78.15.52 (voice); +33 475.78.15.50 (fax). E-mail: philippe.sarrazin@ujf-grenoble.fr 


\begin{abstract}
Previous studies in educational settings have examined the relations between students' intrinsic and extrinsic motivation and relevant outcomes. In most of those studies a global indicator of self-determined motivation as defined by Self-Determination Theory was created to examine the relations between motivation as a global construct, its antecedents and specific outcomes. The purpose of this paper was to extend this line of research by examining (1) whether the different types of motivation proposed by SDT can combine into distinct profiles as identified by cluster analysis and (2) the links between those profiles and objective criteria of achievement. In Study 1, motivation toward physical education was assessed at the beginning of a 10-week gymnastics teaching cycle and performance was assessed at the end of the cycle, among a sample of high school students $(\mathrm{N}=215)$. Study 2 $(\mathrm{N}=210)$ extended the results of Study 1 by controlling the initial performance of the students, measuring the effort they exerted and recording the grade obtained. Cluster analyses revealed three motivational profiles: self-determined, non self-determined and moderate levels of both types of motivation. Path analysis showed that the self-determined profile was related to the best level of achievement. The results are discussed in terms of their implications for the assessment of students' motivational profile and the consequences that those profiles may have for educational outcomes.
\end{abstract}

Key words: self-determination theory, motivational profile, achievement. 
Students' Motivational Profiles and Achievement Outcomes in Physical Education: A Self-

\section{Determination Perspective}

The importance of motivation in education is unquestionable. As decades of research in educational settings have stressed, motivation is a consistent and a significant contributor to students' functioning and performance (Good \& Brophy, 2000). However, throughout the past 20 years, research using the framework of Self-Determination Theory (SDT; Deci \& Ryan, 1985, 2000; Vallerand, 1997) has shown that individuals in general and students in particular, differ considerably in the ways they could be motivated toward an activity. More importantly, those differences in individuals' motivational orientations have far-reaching influences on their approach of an activity and the consequences that follow (see Deci \& Ryan, 2000, for a review). This comprehensive framework holds the potential to contribute significantly to our understanding of the issues related to motivation in education for the following reasons. First, it distinguishes between different types of motivation that can have a distinct impact on the maintenance and integration of behavior. Second, it presents clear hypotheses regarding the conditions that should hinder or facilitate students' motivation. Third, it outlines various consequences (cognitive, affective, and behavioral) that are associated with the different types of motivation (Vallerand, 1997). Fourth, it addresses the issue of internalization, the process by which behaviors that were initially reinforced by external sources (e.g., parents or teachers) become integrated within the individual to form a permanent part of his or her self.

In spite of the tremendous progress that has been made in this area of inquiry, some of the more basic questions concerning motivation conceptualization and measurement have remained relatively unexamined. One of the unexamined issues concerns the representation of the multiple forms of motivation proposed by SDT. Few studies have examined how these different goals combine to influence students' achievement behavior. In the present 
studies, we used cluster analysis in order to examine how the different forms of motivation proposed by SDT combine with each other and in order to examine how they relate with students' academic performance in Physical Education (PE) classes. Two prospective studies were conducted in order to look at the links between the motivational profiles observed in a natural class setting, and objective achievement criteria such as performance, overt effort and grade. In the next part we present the different motivational orientations assumed by SDT, as well as the links observed between those constructs and various academic outcomes. Then we explain how the different types of motivation have been used in passed literature, and the problems that arise. Finally, we present the specific purposes of the two studies.

\section{The SDT Motivational Continuum}

Research clearly supports the idea that individuals have different motivational orientations. They can be intrinsically motivated, when they are engaging in activities for their inherent satisfaction, extrinsically motivated, when they are engaging in activities for instrumental reasons, or amotivated, when they prove no regulation toward an activity. According to recent research, intrinsic motivation (IM) could derive from several sources. For instance, Vallerand (1997; Vallerand, Blais, Brière, \& Pelletier, 1989) distinguishes between IM to experience stimulation, when individuals are motivated by feeling pleasant sensations, IM toward knowledge, when they are moved by the desire to explore and learn new things, and IM toward accomplishment, when they aim at improving themselves.

Research also supports distinctions regarding the different types of motivation that fall in the category of extrinsic motivation. The first two forms of extrinsic motivation are labeled respectively external, when the individuals' behavior is controlled by external sources, and introjected, when they have internalized the formerly external source of motivation but have not yet truly accepted the behavior. For these reasons they are referred 
to as non self-determined or controlled. The next two kinds of extrinsic motivation, on the other hand, represent self-determined, or autonomous, types of regulation. A distinction is made between identified regulation, which refer to a situation where individuals perform an activity that has personal importance, and integrated regulation, where individuals have integrated a behavior within their set of goals and values. Finally, the lowest level of selfdetermination proposed by SDT is amotivation. Amotivated individuals lack perceived competence, because they do not feel able to perform the behavior, or perceived control, because they think their actions will not be adequate or sufficient to achieve a desired outcome (Deci \& Ryan, 2000).

\section{The Outcomes of Motivation}

A considerable amount of research examined the relations between the different types of motivation and positive and negative outcomes. It has been observed that IM and selfdetermined forms of extrinsic motivation (i.e., identified and integrated regulations) have been linked to the more positive outcomes, whereas non self-determined forms of motivation (i.e., external and introjected regulations) and amotivation have been linked to the less positive ones (Ryan \& Deci, 2000; Vallerand, 1997). In education, there is evidence since the early nineties that self-determined motivation toward school is related to several important outcomes (see Deci, Vallerand, Pelletier, \& Ryan, 1991; Reeve, 2002, for reviews), including students' level of achievement (e.g., Burton, Lydon, D’Alessandro, Koestner, 2006; Miserandino, 1996), coping style (e.g., Ryan \& Connell, 1989), preference for optimal challenges (e.g., Boggiano, Main, \& Kantz, 1988), creativity (e.g., Amabile, 1985), well-being (Levesque, Zuehlke, Stanek, \& Ryan, 2004), and persistence for a class (Vallerand \& Bissonette, 1992) and for school (Vallerand, Fortier, \& Guay, 1997).

Although research has been scarcer in the physical activity context, a growing body of research confirms this pattern of results in that domain. Self-determined motivation has 
been linked to higher levels of self-reported effort in sport (Pelletier, Fortier, Vallerand, Tuson, Brière, \& Blais, 1995) and exercise (Fortier \& Grenier, 1999), and to lower levels of sport dropout (Pelletier, Fortier, Vallerand, \& Brière, 2001; Sarrazin, Vallerand, Guillet, Pelletier, \& Cury, 2002). Also, self-determined motivation for physical education has been linked to the intention of being physically active or playing sport in the future (e.g., Ntoumanis, 2001; Standage, Duda, \& Ntoumanis, 2003), to concentration, positive affect and preference for challenging tasks (Standage, Duda, \& Ntoumanis, 2005), to self-reported (Goudas, Biddle \& Underwood, 1995; Ntoumanis, 2001; 2002) or teacher reported effort (Ferrer-Caja \& Weiss, 2000; Standage, Duda, \& Ntoumanis, 2006), to persistence and performance (Vansteenkiste, Simons, Lens, Sheldon, \& Deci, 2004, study 3) and negatively linked with boredom (Ntoumanis, 2001; 2002) or feelings of unhappiness (Standage, et al., 2005).

\section{The Operationalization of Motivation}

In order to test the SDT hypotheses, researchers have been faced with some crucial questions about the best ways to use the different types of motivation as determinants of various outcomes. Generally, correlational or experimental methods were used to examine relations between single goals and criterion measures (e.g., Ryan \& Connell, 1989; Vansteenkiste et al., 2004). Sometimes, multiple regression analyses or structural equation modeling were used in order to test if goals have independent and additive effects for achieving a particular outcome (e.g., Ntoumanis, 2001; Pelletier et al., 2001). Finally, a major part of the studies integrated the scores obtained for the different types of motivations into a self-determination index (e.g., Ryan \& Connell, 1989). This index relies on an interactional hypothesis (Vallerand \& Fortier, 1998), according to which intrinsic and extrinsic motivations are not independent, and a high level of one kind of regulation is necessarily linked to a low level of the other. The Self-Determination Index is generally 
calculated by giving each subscale a specific weight according to its respective place on the self-determination continuum (i.e., $+3+2,+1,-1,-2$, and -3 , respectively, for IM, integrated, identified, introjected and external regulation, and amotivation scales). Next, the weighted scores of each subscale are added to derive a single index (e.g., Levesque et al., 2004; Miserandino, 1996; Vallerand et al., 1997). An important element in favor of the SelfDetermination Index is the support for a matrix simplex in the continuum of selfdetermination. A matrix simplex is observed when the correlation between measures of two motivational constructs tends to decrease as the distance between them on the theoretical continuum increases. For example, because of its position on the theoretical continuum of self-determination, IM should be highly correlated with identified regulation, but negatively correlated with amotivation. Its correlations with introjected and external regulation should take values comprised between the two others. This pattern of correlations has been observed in several domains, including education (e.g., Vallerand, Pelletier, Blais, Brière, Senécal, \& Vallières, 1993), sport (e.g., Pelletier et al., 1995) and exercise (Li, 1999). However, several recent studies raised questions concerning the hypothesized motivational continuum, because the correlations among the ordered subscales provided only limited support for the simplex pattern (e.g., Cokley, 2000; Fairchild, Horst, Finney, \& Barron, 2005). For example, Fairchild et al. (2005) found that external regulation score is rather independent from the three intrinsic motivation scores (between .05 and .21). These results support the proposition that intrinsic and extrinsic motivation are not necessarily mutually exclusive, but rather independent constructs (e.g., Amabile, Hill, Hennessey, \& Tighe, 1994; Covington \& Muëller, 2001; Lepper \& Henderlong, 2000). For example, Covington and Muëller (2001) underlined that "the weight of recent evidence suggests that intrinsic and extrinsic tendencies may best be conceived as two independent orientations, not just two endpoints on a single continuum" (p. 163). In this case, as Fairchild et al. (2005) 
noted "[p]erhaps one needs to consider how subscales combine or interact to promote motivation" (p. 335).

Little research was carried on the various ways to represent and group the different types of motivation proposed by SDT, in spite of the call of certain authors to examine how they combine into distinct motivational profiles (Vallerand, 1997). This preoccupation is shared by other authors, such as Sansone and Harackiewicz (2000), who concluded their book on Intrinsic and extrinsic motivation underlining that "the challenge that confronts theorists now is to specify how individuals might pursue more than one goal at a time and to detail the motivational dynamics of multiple goal pursuit." (p. 450). In the present article, we are proposing that a pattern-centered approach is suitable for situations where several factors might act in conjunction with each other. It is especially the case when moderate or high correlations exist between several factors, which can undermine the efficacy of classical regression approaches (Mosteller \& Tukey, 1977).

A particularly useful method to examine this issue is cluster analysis. This statistical technique identifies homogeneous groups, or clusters, based on the shared characteristics they possess (Härdle \& Simar, 2003). Therefore, the groupings obtained allow the researcher to examine differences between profiles rather than looking at inter-individual differences. This kind of analysis should be helpful to determine if, in conformity with the SDT hypothesis, self-determined or non self-determined profiles can be observed in natural settings, and/or if, in conformity with the additive hypothesis, motivational profiles combining high levels of self-determined as well as non self-determined motivation emerge.

Recently, several studies used cluster analysis to examine motivational profiles in the educational (e.g., Braten, \& Olaussen, 2005; Meece \& Holt, 1993; Ntoumanis, 2002; Wang, Chatzisarantis, Spray, \& Biddle, 2002), sport (Hodge \& Petclichkoff, 2000; McNeill \& Wang, 2005; Vlachopoulos, Karageorghis, \& Terry, 2000), and physical activity settings 
(Biddle \& Wang, 2003; Marshall, Biddle, Sallis, McKenzie, \& Conway, 2002; Wang \& Biddle, 2001), some of them being based on achievement goal theory (e.g., Meece \& Holt, 1993), SDT (Ntoumanis, 2002; Vlachopoulos et al., 2000) or a mix between both theories (e.g., Biddle \& Wang, 2003; Wang et al., 2002). Two of these studies examined specifically the different motivations proposed by SDT. Vlachopoulos et al.'s (2000) found among two large samples of athletes one profile higher on self-determined forms of motivations and lower on non self-determined forms of motivation, as well as one profile with relatively high scores on every kind of regulations and low scores on amotivation. None of the obtained profiles showed higher scores on non-self-determined than on self-determined forms of motivations. The authors suggested that athletes with those profiles may have ceased their sport participation, and therefore could not be part of the sample anymore.

The motivational profiles observed by Ntoumanis (2002) in physical education were quite different. In a cross-sectional study, he questioned two samples of British students about their experience in physical education. The questionnaire included self-reported measures of motivational climate, self-determined motivation, effort, enjoyment and boredom. The data collected in the first school were used to conduct an exploratory cluster analysis, whereas the data from the second school were used to conduct a confirmatory analysis. The same three profiles emerged. In the first one, students displayed high levels of self determined motivation but low levels of external regulation and amotivation. In another cluster, students showed low scores for self-determined kinds of motivation, moderate scores of introjection, and high scores of external regulation and amotivation. The third profile was characterized by average scores for every form of regulation. These results have to be interpreted cautiously, however, because antecedent (motivational climate), consequences (e.g., boredom) and motivations were analyzed at the same time. In other words, the profiles observed in this study were not, strictly speaking, motivational profiles, because the 
numerous variables entered in the analysis may have influenced the results. It seems more appropriate to treat only the motivational scores with such an analysis, and afterwards to examine how the motivational profiles are related to certain important outcomes.

\section{The Current Studies}

With the recent shift in interest for the possible ways to combine the different types of motivation proposed by SDT (i.e., the use of the Self-Determination Index versus the use of different clusters), a key question concerns the relative predictive power of the different types of motivational profiles that could result from clusters analysis. That is, should motivation researchers who are interested in predicting important outcomes in education, such as involvement, performance, or grade, consider more than one way to combine the different forms of motivation proposed by SDT, and are some ways better suited to the prediction of some outcomes over others?

Accordingly, the purpose of this paper was twofold. First, we examined whether the three profiles observed by Ntoumanis (2002) in a sample of British students would emerge among students from another country, when considering only motivational variables in the grouping analysis. The interest of this replication is both theoretical and empirical. From a theoretical perspective, it is not clear yet how the different kinds of motivation proposed by SDT should be combined. If a cluster analysis reveals only self-determined or not selfdetermined profiles of individuals, this would give support to the hypothesis of a continuum of motivation in the educational context. On the other hand, if cluster analysis reveals students' profiles with high levels of both self-determined and non self-determined motivation, it would support the hypothesis that those two kinds of motivation can combine in naturalistic settings. Indeed, Lepper and Henderlong (2000) argued that "[...] despite the experimental demonstrations that superfluous extrinsic contingencies can undermine intrinsic interest in controlled experimental contexts, [we think that] intrinsic and extrinsic 
motivation may, in many real-word settings, exert simultaneous positive influences on behavior." (Lepper \& Henderlong, 2000, p. 273). From an empirical point of view, there is great interest to know which motivational profiles actually exist in an academic setting like physical education classes, in which proportions students display such profiles.

In line with the finding of Ntoumanis (2002), two clusters coherent with the SDT hypothesis were expected to emerge, that is where low levels of self-determined forms of motivation would be present with high levels of non self-determined forms of motivations, and vice versa. We also expected the emergence of a third cluster which shows average levels of every kind of motivation. In order to reach this goal, an exploratory (Study 1) and a confirmatory (Study 2) cluster analysis were conducted on two separate samples of French high school students.

Second, we wanted to examine the consequences that those motivational profiles may have for behavioral variables representative of students' achievement (like effort, performance and grade). It is important to emphasize that common limitations encountered in several of past studies conducted in education or in physical education were that most of the outcomes were assessed with self-reported measures and that these studies used a crosssectional design (e.g., Ntoumanis, 2001; Ntoumanis, 2002; Standage et al., 2003, 2005). One problem with this procedure is that the links observed between self-reported measures from the same source may be inflated by shared variance rather than due exclusively to actual relations. Moreover, the absence of a longitudinal design limits the possibilities of inferring causality among the variables. We thus chose to use objective measures of students' achievement, and to adopt a prospective design. In Study 1, we tested whether motivational profile would be linked to final performance, assuming that the more selfdetermined the profile of a student (i.e., high scores on self-determined scales and low scores on non self-determined ones), the better would be his/her final performance. In Study 2, a 
more complex design was adopted, in order to examine in more details the role that motivational profile may play in the achievement process. Insofar as initial motivational profile might not be independent from initial performance, it seemed important to examine the relation between motivational profile and final performance, while controlling for student's initial performance, if we wanted to reinforce the idea that motivational profile actually has an effect on achievement. Grade and provided effort were also assessed as achievement outcomes.

\section{Study 1}

\section{Method}

\section{Participants and Procedure}

Two hundreds and ten students (104 girls, 104 boys; 2 students did not specify gender) from a French high school volunteered to participate in the study. They came from $6^{\text {th }}$ grade $(N=73), 7^{\text {th }}$ grade $(N=70)$ and $9^{\text {th }}$ grade $(N=67)$ classes $^{1}$. Their age ranged between 10.7 and 16.8 years old $(M=13.26 ; S D=1.49)$. In France, physical education is a compulsory subject for all high school students. Generally, teachers teach different sports and physical activities in 10-week cycles (i.e., 10 lessons of 2 hours). The study was conducted during gymnastics cycles in scheduled physical education lessons. Prior to the initiation of the research, teachers, parents, students and school administrators were asked to participate in an observational study. Students' motivations for the activity were assessed during the first lesson. At the end of the cycle, all students were videotaped individually in order to evaluate their performance in gymnastics.

\section{Measures}

Motivation. Motivation toward gymnastics was assessed at the beginning of the cycle. An adaptation of French motivation scales in sport (i.e., the "Echelle de Motivations dans les Sports"; Brière et al., 1995) and education (i.e., the "Echelle de Motivation 
Académique"; Vallerand et al., 1989) and of a scale developed in english to assess physical education motivation (Standage, Duda, \& Ntoumanis, 2006), was used in order to fit both the sportive and educational aspects of physical education. These three tools assess the multifaceted motivational regulations proposed by SDT. Depending on the subscale, the items were preferentially adapted from one tool or the other. For example, the IM scales were mainly derived from the EMS. The adaptation consisted of minor changes in the wording of some items to target the gymnastics context and/or a translation in French. Six motivational constructs relative to physical education were assessed in a 18 -item scale. The participants had to complete the following sentence "I participate in gymnastics classes..." with items reflecting IM to experience stimulation (e.g., “... for the excitement I feel when I am really involved in the activity"), IM toward knowledge or accomplishment (e.g., “...for the satisfaction I experience while I am perfecting my abilities") ${ }^{2}$, identified regulation (e.g., “... because what I learn in this activity will be useful later"), introjected regulation (e.g., “... because I would feel guilty if I could not succeed in this activity”), external regulation (e.g., “...Because that's what I'm supposed to do"), and amotivation (e.g., "I don't know why I go in gymnastics, if I could, I would get exempted"). An English version of the entire scale is presented in Table 1. Responses were made on a 7-point scale ranging from 1 (strongly disagree) to 7 (strongly agree).

Performance in gymnastics. Students' performance in gymnastics was based on a test consisting of five basic gymnastics exercises (e.g., stretched handstand back drop, backward roll, and cartwheel). The students were videotaped one by one during a class prior to the initiation of the gymnastics cycle. Three experts in gymnastics rated the videotaped performance of each student on a 1 (low level) to 7 (high level) response scale. Each of them looked at the videotapes individually, and made a single global rating of the student's performance after viewing all five exercises. Inter-judge reliability was very good $(\alpha>.90)$. 
The mean of the three experts' scores was calculated and used as an indication of students' gymnastics performance. This procedure has been used previously in studies involving physical education classes (e.g., Chanal, Marsh, Sarrazin, \& Bois, 2005).

\section{Data Analysis}

First, a confirmatory factor analysis was carried out (using Lisrel 8.54, Jöreskog \& Sörbom, 2003) in order to examine the factorial structure of the questionnaire assessing students' motivation. Next, the correlations between motivational scores were examined Afterwards, an exploratory cluster analysis was conducted in order to examine how much motivational profiles could be identified. An examination of the cluster composition according to gender and school year was then carried out. Finally, an analysis of variance (ANOVA) was done in order to test whether motivational profiles were linked to final performance.

\section{Results and Discussion}

The means and standard deviations of the variables are shown in Table 2, as well as the alpha coefficients and correlations among variables.

\section{Confirmatory Factor Analysis}

The structure we tested was supposed to rely on 6 factors, namely: IM toward stimulation, IM toward knowledge or accomplishment, identified regulation, introjected regulation, external regulation, and amotivation with three items expected to load on each factor. A test carried out in order to evaluate the normality of the distribution of the variables revealed that none of them was normally distributed (multivariate skewness and kurtosis tests, $p s<.0001$ ). We thus chose to use the robust maximum likelihood estimation procedure. The analysis showed a relatively good fit of the six-factor structure with the data: $\chi^{2}(120)=304 ; p<.01 ;$ robust $\mathrm{CFI}=.97 ; \mathrm{NNFI}=.96 ; \mathrm{SRMR}=.06 ; \mathrm{RMSEA}=.07 ; 90 \% \mathrm{CI}$ of RMSEA $=.057-.082$. The factors loadings were all significant at the .01 level and 
ranged between .37 and $.93(M=.74)$. They are presented along with the corresponding items in Table 1.

Simplex Pattern

Correlations among the constructs are shown in Table 2. The correlations between the variables appear to be in conformity with a simplex ordered matrix, although we found some deviations from this presumed pattern. For example, IM toward knowledge or accomplishment displayed a more important relationship with identified regulation (.75) than with IM toward stimulation (.65). More important, introjected regulation showed strong positive correlations with IM toward Stimulation (.52), IM toward Knowledge or Accomplishment (.62) and Identified Regulation (.59), no correlation with External Regulation (-.02, ns) and only moderate negative correlations with Amotivation (-.25). Cluster Analysis

Given that the internal consistency of each sub-scale proved to be satisfactory (see Table 2), the average of the scores was calculated for each one. A cluster analysis was next conducted, following the procedure suggested by Hair, Anderson, Tatham and Black (1998). All the variables included in a cluster analysis have to share the same metric, so that each of them contributes equally to the formation of the clusters. All the motivational constructs were assessed on a 7-point scale. Cluster analysis is also sensitive to outliers. Preliminary analyses showed no cases with a distance from the mean greater than three times the value of standard deviation. Finally, multicollinearity between variables may impact on the cluster analysis by giving more weight to collinear variables. Given that no Bravais-Pearson correlation coefficient was higher than .90 , we considered that there was no problem of this kind (Hair et al., 1998)

A hierarchical cluster analysis was performed using Ward's method with a squared Euclidean distance measure. The agglomeration schedule and dendrogram were used to 
identify the number of clusters. A high increase of the agglomeration schedule (37\%) suggested a three-cluster solution to be suitable. Figure 1 shows the profiles of those three clusters. The first cluster was labeled "self-determined" profile and represented $35 \%$ of the sample $(N=73)$. Students in this cluster showed high levels of self-determined forms of motivation (i.e., IM and identified regulation), moderate level of introjected regulation, and low levels of external regulation and amotivation. The second cluster was labeled "moderate" profile" and also represented $35 \%$ of the sample $(N=73)$. Students in this cluster had average scores for every form of motivation, with a majority of scores close to 3 and 4 on a 7-point scale. The third cluster was labeled "non self-determined" profile and represented $30 \%$ of the sample $(N=64)$. Students in this cluster displayed low levels of self-determined forms of motivation (i.e., IM and identified regulation), a low level of introjected regulation and relatively high levels of external regulation and amotivation. The clusters' size, as well as the means and standard-deviations of their centroid, are showed in Table 3.

A MANOVA showed a significant effect of cluster membership on the six motivational constructs (see Table 3) [Wilk's lambda $=.13$; Rao $R(12,404)=58.29 ; p<$ .001]. Follow up ANOVAs revealed a significant effect of cluster membership on each motivational construct (the values of $F, p$ and $\eta^{2}$ are indicated in Table 3). Newman-Keuls post-hoc analyses $(p<.01)$ indicated that the three groups were significantly distinct from each other on all motivational scales, except for introjected regulation between the moderate and self-determined profiles, and for external regulation between the non self-determined and moderate profiles ${ }^{3}$.

\section{Motivational Profile and Gymnastics Achievement}

An ANOVA was carried out in order to test whether motivational profile was linked to different levels of achievement among students, represented by their final performance in 
the activity. The analysis was significant: $F(2,112)=5.37, p<.01, \eta^{2}=.09$. Newman Keuls post-hoc analyses $(p<.01)$ revealed that the three clusters were distinct on final performance in gymnastics (see Table 3), with students in the self-determined cluster showing the highest average performance $(M=4.70)$, followed by the moderate $(M=3.93)$ and the non self-determined cluster $(M=3.51)^{4}$.

Globally, this result is coherent with the tenets of SDT, and with previous research in education (e.g., Reeve, 2002). However, the result relative to introjected regulation is somewhat surprising. As a non self-determined form of regulation, it is theoretically assumed to lead to negative consequences. In the present study it was found to be linked to better achievement. In the sport context, introjection has been found previously to be related to short term persistence (Pelletier et al., 2001) but not to long-term persistence. Maybe it deserves to be considered a potential positive form of motivation at a short term level.

This study also reveals the existence of a third motivational profile, which comprises students with moderate scores for all motivational scales. It thus seems possible to combine both self-determined and non self-determined forms of motivation when they remain moderately developed. The analysis did not show a profile with high scores on the majority of sub-scales. The analyses showed that students with this moderate profile globally realized better performances than students with a non self-determined profile, but poorer performances than students with a self-determined profile.

Even if a prospective design was adopted in this study, the correlational nature of the data does not allow us to affirm that the different motivational profiles observed were the cause for different levels of performance at the end of the cycle. In other words, we cannot ignore the possibility that differences in initial performance are responsible for the motivational profiles observed. It thus seemed important to control for initial performance in order to evaluate more accurately the potential impact of motivation on final performance. 
Moreover, criteria other than performance should also be used as representative of achievement.

\section{Study 2}

The aim of Study 2 was first to verify that the motivational profiles observed in Study 1 could be validated in another sample of students. Second, we wanted to test the effect that those motivational profiles may have on performance, controlling for initial performance, as well as the role that these variables and exerted effort may play in the prediction of final grade.

According to SDT, it was hypothesized that the more self-determined the profile of the students, the greater effort, performance and grade would be. More precisely, the best consequences were expected to be achieved by students displaying a self-determined profile, followed by students showing a moderate profile. Students with a non self-determined profile were expected to show the lowest level of achievement. Our hypothesized model of achievement (see Figure 2) comprised three dependant variables. The effort exerted by the students was expected to be related to both their initial performance in the activity and to their motivational profile. Their final performance was expected to be related to their initial performance, their motivational profile, and their effort. In other words, for a similar initial performance in the activity, we expected that putting more effort and being more selfdetermined for the activity would result in higher improvement, and thus in a higher final performance. Finally, the grade obtained was hypothesized to depend on students' final performance, but also on initial and middle cycle variables, that is their initial performance and motivation, as well as the objective effort they exerted. Teachers, and particularly physical education teachers, have been shown to prefer hardworking students, whatever their level of ability (Covington \& Omelich, 1979; Weiner, 1979; Biddle \& Goudas, 1997). 
Moreover, teachers might take into account initial characteristics of their students (e.g., performance and motivation) to form expectations on their achievement, which may impact on the grade they give them at the end of the cycle (e.g., Jussim \& Eccles, 1992; Trouilloud, Sarrazin, Martinek, \& Guillet, 2002).

\section{Method}

\section{Participants and Procedure}

Two hundreds and fifteen students (99 girls, 116 boys) from a French high school volunteered to participate in the study. They came from $7^{\text {th }}$ grade $(N=115), 8^{\text {th }} \operatorname{grade}(N=$ $70)$ and $9^{\text {th }}$ grade $(N=30)$ classes. Their age ranged between 10.5 and 16 years old $(M=$ $12.47 ; S D=1.05$ ) and all of them were involved in a gymnastics cycle. During the first lesson, students' motivation and their initial performance in the activity were assessed. Next, students effort in gymnastics was measured in the middle of the cycle (i.e., between the $4^{\text {th }}$ and $6^{\text {th }}$ gymnastics courses). Finally, students' performance in gymnastics was appraised during the last class, and their grade was recorded.

\section{Measures}

Motivation. The same scale than in Study 1 was used.

Performance in gymnastics. The assessment of students' performance in the activity at the beginning and at the end of the teaching cycle was identical to Study 1 .

Effort in gymnastics. In the middle of the cycle, a videotape was used to evaluate the amount of effort provided by the students. The camcorder was placed in a fixed spot, in order to record the activity of the students when they worked on the stretched handstand back drop task. Several students were involved in this workshop simultaneously, but there was enough space so that they could work at it at the same time. Furthermore, teachers were previously informed of the purpose of the camcorder, and were asked not to interact with 
students completing this exercise. The number of repetitions of the exercise for 5 minutes was calculated and used as an indication of their investment in the activity.

Grade. After completion of the gymnastics cycle, all teachers provided the grades obtained by the students in gymnastics. French grades are scores comprised between 0 and 20 , and the score of 10 is usually considered a mediocre result.

\section{Data Analysis}

A confirmatory cluster analysis was conducted on the sample, taking the number of clusters emerging in Study 1 as a basis for the analysis. Next, the hypothesized model of achievement (see Figure 2) was tested using path analysis.

\section{Results and Discussion}

The means and standard deviations of the variables are shown in Table 4, as well as the alpha coefficients for multi items variables and Bravais-Pearson correlations among all variables.

\section{Confirmatory Cluster Analysis}

A k-mean cluster analysis was conducted, based on the result of the hierarchical cluster analysis carried out in Study 1. This kind of analysis is considered confirmatory, because it requires the researcher to provide a specific number of clusters expected to emerge in the sample. In line with the result obtained with the first sample, the fact that the second sample was comparable in terms of age and gender, and that it originated from a school presenting relatively similar characteristics, the number specified in the cluster analysis was set at three. A MANOVA showed a significant multivariate main effect of cluster membership on motivational scores: [Wilk's lambda $=.12$; Rao $R(12,420)=64.66$; $p<.01]$. Follow-up ANOVAs showed that cluster membership led to a significant effect on each motivational construct $\left(p s<.001, \eta^{2}>.29\right)$. Newman-Keuls post-hoc analyses $(p<$ 
.01) revealed that the three groups were significantly distinct from each other on all motivational scales. The motivational profiles were similar to those observed with the hierarchical procedure in Study 1 (see Figure 3), with little change regarding the repartition of the students in the various clusters. The self-determined profile represented $39 \%$ of the sample $(N=84)$, the moderate profile $42 \%(N=91)$ and the non self-determined profile $19 \%$ $(N=40)$. Students in the non self-determined profile demonstrated higher scores for external regulation and amotivation than those in Study 1. The clusters' size, as well as the means and standard-deviations of their centroid, are showed in Table 4.

\section{Motivational Profiles and Achievement Outcomes}

The hypothesized model (see Figure 2) was tested with path analysis using Lisrel 8.54 (Jöreskog \& Sörbom, 2003). Two contrasts were computed in order to compare the motivational profiles. The use of contrasts is considered as particularly appropriate in situations were specific hypotheses are formulated by the researcher concerning between groups differences on a dependant variable (Cohen, Cohen, West, \& Aiken, 2003). We expected students with a self-determined profile to show the best level of achievement, followed by students with a moderate profile, and finally students with a non self-determined profile. In order to compare students with a non self-determined versus moderate profile, the weights used to compute the first contrast were $-1,0$, and 1 , for the non self-determined, self-determined, and moderate profiles, respectively. The second contrast compared students with a moderate versus self-determined profile. The weights were $-1,0$, and 1 , for the moderate, non self-determined and self-determined profiles, respectively. A covariance matrix was used with the maximum likelihood estimation method. Because the model we tested was saturated, no adjustment fit indices are given. Only the weights of the paths as well as their level of significance are indicated in Figure 4. 
The analysis revealed that final performance was predicted by the motivational profiles, controlling for initial performance $(\beta=.62)$. Students with a moderate profile obtained better performances than those with a non self-determined profile $(\beta=.27)$, and students with a self-determined profile obtained better performances than those with a moderate profile $(\beta=.30)^{5}$. The two contrasts and initial performance explained $52 \%$ of final performance's variance. On the other hand, students' final grade was predicted by their final performance $(\beta=.44)$, their objective effort $(\beta=.13)$, and their motivational profile, while controlling for their initial performance in gymnastics $(\beta=.27)$. More specifically, as it was the case for final performance, students with a moderate profile obtained better grades than those with a non self-determined profile $(\beta=.23)$, and students with a self-determined profile obtained better grades than those with a moderate profile $(\beta=.25)$. Altogether those variables explained $59 \%$ of students' grade variance. Objective effort was predicted by students' motivational profile while controlling for initial performance $(\beta=-.05 n s)$. Students with a moderate profile exerted more effort than those with a moderate profile $(\beta=$ .21), whereas there was no significant difference between students with a moderate or selfdetermined profile $(\beta=.15 n s)^{6}$.

Taken together, the analyses showed that students who showing a self-determined profile were those who achieved the most during the cycle: they provided more effort, realized the best final performance, and obtained better grades than the students showing alternative profiles. By opposition, students who showed a non self-determined profile were those who achieved the less. A moderate motivational profile with average scores on all sub-scales was found to be linked to in-between achievement scores. One could assume that students showing this type of motivational profile are willing to provide effort in some certain circumstances, for example if self-consciousness is salient. This might have been the case in this study, as the camcorder was visible and thus some students may have tried to do 
the exercise just because this effort would be noticed. This could explain why no significant difference was observed between the moderate profile and the self-determined profile for this variable. However, this "superficial" effort does not seem sufficient to make progress, since there was actually a significant difference in terms of final performance between those two groups, even after controlling for initial performance in the activity.

\section{General Discussion}

Several authors have recently called on researchers to begin to pay attention to the possible ways to combine different types of motivation, and more specifically, the different types of motivation proposed by SDT (Fairchild et al., 2005; Vallerand, 1997). The purpose of this paper was to adopt an original approach to examine students' motivation and the potential consequences that conceptualizing and regrouping different forms of motivation may have in education. More specifically, we chose to adopt a pattern-centered approach, instead of testing specific effects of each motivational construct from SDT, or using an aggregated index of self-determination. That is, we examined how the different types of motivation combined into certain profiles, and how those profiles were related to students' achievement. On one hand, recent research suggests that the Self-Determination Index may not be the only way to represent the different types of motivation proposed by SDT (e.g., Fairchild et al., 2005). On the other hand, looking at the separate effects of the different forms of motivation does not take into account the relationships between those motivations. Two longitudinal studies were conducted in a natural Physical Education setting in order to examine those issues.

\section{Description of the Motivational Profiles}

Cluster analyses were conducted to examine which motivational profiles would emerge in our samples. Overall, the results confirmed those observed by Ntoumanis (2002) with British students, even if the procedure we adopted was not strictly identical. We 
observed two profiles with a clear motivational orientation toward either one extremity of the theoretical continuum proposed by SDT (e.g., Deci \& Ryan, 2000). These profiles provided support for the interactional hypothesis about the relations between motivational constructs (e.g., Vallerand \& Fortier, 1998). The first cluster was oriented toward the selfdetermined part of the continuum of motivation, with high levels of IM and identified regulation, moderate levels of introjected regulation, and low levels of external regulation and amotivation. A second cluster was oriented toward the non self-determined part of the continuum, with students scoring high on external regulation and amotivation, and low on other forms of motivation. The third motivational profile we observed presented average scores on each motivational variable. As proposed by some authors (e.g., Lepper \& Henderlong, 2000) it is possible that intrinsic and extrinsic forms of motivation combine in real-word settings. The results observed within our samples suggest that this can be the case if the level of those motivations remains moderate (see figure 3). Compared to the results of Ntoumanis (2002), the repartition of the students in the clusters was rather similar for the "moderate" motivational profile, but less French students displayed a "self-determined" profile and more of them showed a "non self-determined" profile. These differences can be explained by the fact physical education is compulsory for all high school students in France.

\section{Motivational Profile and Achievement}

The second purpose of the studies was to examine the relations between motivational profiles and achievement in physical education. For both studies, we assessed achievement variables at different moments during the 10 -week cycle. A longitudinal design is particularly appropriate because motivation is likely to have an impact on the variables of interest through time. Achievement was evaluated thanks to three objective criteria, instead of the self-reported measures usually used in educational studies. First, a videotape was used to evaluate the effort exerted by the students during a task completion (Study 2). 
Second, we used the same procedure to assess students' initial performance in gymnastics (Study 2), as well as their performance 10 weeks later (Studies 1 and 2). Finally, the grade obtained for the class was provided by the teachers (Study 2).

A first hypothesis concerned the relationship between motivational profile at the beginning of the cycle, and final performance in the activity at the end of the cycle. In Study 1, motivational profile was actually found to be significantly linked to students' final performance. The more students displayed a self-determined profile of motivation, the highest was their performance. This positive link was previously observed in education (e.g., Miserandino, 1996), but with a cross-sectional design. The analyses conducted in Study 2 indicated that the students' motivational profile was significantly linked to their final performance, even after controlling for their initial performance. This is particularly important, because even if motivation was measured before performance in previous research, very little effort has been made to disentangle this effect from the effect of initial performance. Our result confirms that no matter the initial level of skills of a student at the beginning of a teaching cycle, the more he/she displays a self-determined profile of motivation toward the activity, the highest will be his/her final performance.

We also examined the link between student's motivational profile and the effort they exerted. This link was significant, when comparing the more self-determined students with the less self-determined ones. Students showing a moderate profile provided tangentially more effort than students with a non self-determined profile, but they were not distinguishable from students with a self-determined profile. Moderate levels of external regulation and amotivation, combined with moderate levels of other motivations was thus found not to have too much negative consequences: it seems that this configuration is likely to promote effort in situations where self-consciousness is made salient, for example when the performance is videotaped. A positive link was already observed in Physical Education 
between self-determined motivation and effort reported by the students themselves (e.g., Ntoumanis, 2001; 2002) or their teacher (e.g., Standage, et al., 2006). The pattern of result observed in our study confirms this past literature, but with a more objective measurement, since the effort of every student was evaluated with a videotape.

Finally, we examined the final grade obtained by the students. We expected that teachers' evaluation would first depend on the other indicators of achievement, namely the students' final performance in the activity and the effort they exerted during the cycle. Indeed, teachers have been found to prefer more invested, hard worker students, whatever their level of performance (Covington \& Omelich, 1979). This hypothesis was confirmed: both indicators were significantly related to students' grade. It means that teachers gave better grades to students that they perceived to work harder, even if they did not reach the greatest level of achievement. Motivational profile showed an indirect association with grade, thanks to its links with the effort provided and the final level of performance. Motivational profile was also found to have positive, direct links with the final grade given by the teacher, as well as the initial performance in the activity. This result suggests that teachers took into account some early characteristics of the students to evaluate them at the end of the cycle. One explanation to this result could be teacher's expectancies (e.g., Jussim \& Eccles, 1992), and more precisely perceptual biases in their evaluation. This phenomenon is based on the influence teacher's early expectancies can have on their judgment of students' performance (e.g., Jussim \& Eccles, 1995). Basically, if teachers have higher expectancies toward students who show a good performance at the beginning of the cycle, this could lead them to over-evaluate their final level (see Trouilloud, et al., 2002). Nevertheless, this hypothesis cannot be verified because teacher's variables were not measured in this study.

Implications for Self-Determination Theory and Research 
This work constitutes a substantial contribution to the SDT literature. Indeed, the representation of the multiple forms of motivation proposed by this theory represents one relatively unexamined issue to date. The motivational profiles observed in theses studies and their links with students' achievement suggest interesting issues regarding the regulatory processes involved in education. The first issue to be addressed concerns the particularly negative pattern observed for students showing a non self-determined profile. The association of high levels of external regulation and amotivation, associated with low level of every other form of motivation, was found to lead to poor effort, performance and grade. A similar profile was previously observed by Ntoumanis and was associated with high levels of boredom, and very low levels of enjoyment and effort (Ntoumanis, 2002). In the sport context, negative independent effects of the degree of external regulation and amotivation have been observed on short and long term persistence (Pelletier et al., 2001). The students displaying such motivational profiles are likely to "suffer from a lack of motivation and a sense of helplessness outside of the specific situations in which extrinsic rewards are available." (Leeper \& Henderlong, 2000, p. 295). One might argue with the exception of when they are evaluated by their teacher, those students might have no motivation at all in class. They are likely to regularly adopt maladaptive strategies and avoid getting involved in the tasks proposed.

Our studies also underscore the particularly adaptive character of a motivational profile combining high scores of intrinsic motivation and identified regulation, but also moderate levels of introjection, and low levels of external regulation and amotivation. The importance of combining intrinsic and identified regulations was already underlined by Koestner and his colleagues (Burton et al., 2006; Koestner \& Losier, 2002). They argue that possessing high levels of both types of regulation could allow one the flexibility to adapt to a wide array of situations. More precisely, combining high levels of both intrinsic motivation 
and identified regulation is likely to lead to high levels of well-being and performance (Burton et al., 2006). More surprisingly, whereas it is considered a non self-determined form of motivation, a moderate level of introjection was finally associated with the higher level of achievement. In spite of the negative affective states it implies, such as anxiety or guilt (Blais, Sabourin, Boucher \& Vallerand, 1990), this kind of regulation could be likely to enhance behavioral involvement. It was found to be related to persistence in previous work (Vallerand et al., 1997; Ntoumanis, 2002; Pelletier et al., 2001), but this relationship was observed only for a short-term period (e.g., Pelletier et al., 2001). The period of our studies was also relatively brief since they concerned 10 -week teaching cycles. It would be interesting to investigate the educational outcomes of motivational profiles on the long-term, in order to verify if this motivational configuration is beneficial for achievement during one or several educational years.

It is important to note that a moderate level of introjection, in itself, does not guarantee those beneficial impacts on achievement. Indeed, students showing similar levels of introjection, associated with moderate levels of other kinds of regulation (i.e., what we labeled moderate motivational profile), did not show identical levels of performance in gymnastics, and that they obtained lower grades. This result suggests that a moderate feeling of guilt, or shame, as shown by the student motivated by introjection, does not necessarily have negative consequences, if at the same time the student gets a certain satisfaction from the activity (i.e., intrinsic motivation), and anticipates that it will help him/her to reach personal goals (i.e., identified regulation). Conversely, when these feelings are not associated with interest or personal value for the activity, the outcomes could be less positive.

Globally our results suggest an adaptive role of the "self-determined" motivational profile, as shown by students with high levels of intrinsic motivation toward stimulation, 
accomplishment and knowledge, high levels of identified regulation, and also moderately high levels of introjection. These elements underscore the importance of the internalization process, thanks to which individuals do not act without feelings of control or competence and without reacting to external contingencies, that is they do not show amotivation or external regulation. This result is coherent with the propositions of Koestner and Losier (2002) who assume that it is appropriate to develop both intrinsic and identified goals. This "dual motivational system" would promote the pursuit of both short term goals, thanks to "the energizing emotions such as interest and excitement" that it implies, and the pursuit of long term goals, that identification is more likely to enhance, because it gives "significance [to] one's current pursuits and fosters positive emotions such as pride in one's accomplishments in the domain" (p. 115).

Past research conducted in education examined how the social context, and more particularly teachers, could influence the degree of satisfaction of students' basic needs and motivations, depending on the motivational climate they generate. The teachers who support autonomy are more likely to generate the internalization of the activity among students. They spend more time listening to their students and acknowledge their perspective, they support more the quality of their performance and progress, and they promote more choice and initiative and participation in decisions (Grolnick \& Ryan, 1989). In contrast, teachers that are controlling use more directives, they give more solutions to the students, criticize them more, and put more pressure on them using rewards, threats, and deadlines. There is empirical evidence showing that the degree to which teachers are autonomy supportive versus controlling is significantly linked with students' need satisfaction and motivations (see Reeve, 2002, for a review), especially in physical education (e.g., Ntoumanis, 2001; Standage, Duda, \& Ntoumanis, 2003). 
Koestner and Losier (2002) also recommend providing a structure to promote selfdetermined forms of regulation. Whatever the way it is delivered, students need to have at their disposal consistent guidelines, rules and expectations relative to their behavior, and a rationale for the tasks and activities proposed. Koestner and Losier (2002) advance that both autonomy support and structure are needed to lead to the internalization of the activity. Even if the educational climate was not taken into account in the present study, this past literature suggests that a teacher showing characteristics of an autonomy supportive climate and providing structure to the students would contribute to the development of a self-determined motivational profile beneficial for achievement.

\section{Limitations and Research Perspectives}

These studies are not exempted of a certain number of limitations. First, the validity of the effort measure can be questioned, since the camcorder was visible. It is thus possible that a social desirability phenomenon occurred, leading some students to put more effort in the task than they usually did. Maybe this can account for the low percentage of variance of this variable explained by the motivational profile, as well as the absence of significance for the path between effort and final performance. Second, the length of the cycle was relatively short, and the effects of motivation observed in 10-week cycles would probably be more important in studies carried out during a whole school year, or with a follow up of students on several years. Indeed, if students practice the same activities each year, the beneficial or detrimental effect of motivational profiles on achievement could be cumulative and lead to greater disparities between students at the end of high school, even if they had the same performance at the beginning. Moreover, the generalization of these results can be questioned, and further studies could replicate those findings in other activities or educational disciplines. Finally, as in many naturalistic studies, we cannot exclude that some of the relationships observed are due to the omission of a relevant variable (see e.g., 
Judd \& McClelland, 1989). For instance, the educational climate provided by the teacher might have had an impact on students' motivation and achievement at the same time. However, given that students' motivation was assessed during the first lesson of the cycle, the potential effect of the teacher climate is limited. Further studies should nevertheless control this variable. 
References

Amabile, T. M. (1985). Motivation and creativity: Effects of motivational orientation on creative writers. Journal of Personality and Social Psychology, 18, 393-397.

Amabile, T. M., Hill, K. G., Hennessey, B. A., \& Tighe, E. M. (1994). The Work Preference Inventory: Assessing intrinsic and extrinsic motivational orientations. Journal of Personality and Social Psychology, 66, 950-967.

Biddle, S., \& Goudas, M. (1997). Effort is virtuous: Teacher preferences of pupil effort, ability and grading in physical education. Educational Research, 39, 350-355.

Biddle, S. J. H., \& Wang, J. C. K. (2003). Motivation and self-perception profiles and links with physical activity in adolescent girls. Journal of Adolescence, 26, 687-701.

Blais, M. R., Sabourin, S., Boucher, C., \& Vallerand, R. J. (1990). Toward a motivational model of couple happiness. Journal of Personality and Social Psychology, 59, 1021 1031.

Boggiano, A. N., Main, D. S., \& Katz, P. A. (1988). Children's preference for challenge: the role of perceived competence and control. Journal of Personality and Social Psychology, 54, 134-141.

Braten, I., \& Olaussen, B. S. (2005). Profiling individual differences in student motivation: A longitudinal cluster-analytic study in different academic contexts. Contemporary Educational Psychology, 30, 359-396.

Brière, N. M., Vallerand, R. J., Blais, M. R., \& Pelletier, L. G. (1995). Development and validation of a measure of intrinsic, extrinsic and amotivation in the sport context : the Échelle de Motivation dans les Sports (ÉMS). International Journal of Sport Psychology, 26, 465-489.

Burton, K.D., Lydon, J.E., D’Alessandro, D.U., \& Koestner, R. (2006). The differential effects of intrinsic and identified motivation on well-being and performance: 
prospective, experimental, and implicit approaches to self-determination theory. Journal of Personality and Social Psychology, 91, 750-762.

Chanal J. P., Marsh H. W., Sarrazin, P. G., \& Bois, J. E. (2005). Big-fish-little-pond effects on gymnastics self-concept : Social comparison processes in a physical setting. Journal of Sport and Exercise Psychology, 27, 53-70.

Chatzisarantis, N. L. D., Hagger, M. S., Biddle, S. J. H., Smith, B., \& Wang, J. C. K. (2003). A meta-analysis of perceived locus of causality in exercise, sport, and physical education contexts. Journal of Sport and Exercise Psychology, 25, 284-306.

Cohen, J., Cohen, P., West, S. G., \& Aiken, L. S. (2003). Applied multiple regression/correlation analysis for the behavioral sciences (3rd Ed.). Mahwah, $\mathrm{NJ}$ : Erlbaum

Cokley, K. O. (2000). Examining the validity of the Academic Motivation Scale by comparing scale construction to self-determination theory. Psychological Reports, $86,560-564$

Cokley, K. O., Bernard, N., Cunningham, D., \& Motoike, J. (2001). A psychometric investigation of the Academic Motivation Scale using a United States sample. Measurement and Evaluation in Counseling and Development, 34, 109-119.

Covington, M. V., \& Omelich, C. L. (1979). Effort: The double edged sword in school achievement. Journal of Educational Psychology, 71, 169-182.

Covington, M. V., \& Muëller, K. J. (2001). Intrinsic versus extrinsic motivation: An approach/avoidance reformulation. Educational Psychology Review, 13, 157-176.

Deci, E. L., \& Ryan, R. M. (1985). Intrinsic motivation and self-determination in human behavior. New York: Plenum.

Deci, E. L., \& Ryan, R. M. (2000). The «what» and «why» of goal pursuits: Human needs and the self-determination theory. Psychological Inquiry, 11, 227-268. 
Deci, E. L., Vallerand, R. J., Pelletier, L. G., \& Ryan, R. M. (1991). Motivation in education: The self-determination perspective. Educational Psychologist, 26, 325-346.

Fairchild, A. J., Horst, S. J., Finney, S. J., \& Barron, K. E. (2005). Evaluating existing and new validity evidence for the Academic Motivation Scale. Contemporary Educational Psychology, 30, 331-358.

Ferrer-Caja, E., Weiss, M. R. (2000). Predictors of intrinsic motivation among adolescent students in physical education. Research Quarterly for Exercise and Sport, 71, 267279.

Fortier, M. S., \& Grenier, M. N. (1999). Déterminants personnels et situationnels de 1'adhérence à l'exercice : Une étude prospective. Staps, 48, 25-37.

Good, T. L., \& Brophy, J. E. (2000). Looking into classrooms $\left(5^{\text {th }}\right.$ Ed). New York: Longman. Goudas, M., Biddle, S., \& Underwood, M. (1995). A prospective study of the relationships between motivational orientations and perceived competence with intrinsic motivation and achievement in a teacher education course. Educational psychology, $15,89-96$.

Hair, J. F., Anderson, R. E., Tatham, R. L., \& Black, W. C. (1998). Multivariate data analysis $\left(5^{\text {th }}\right.$ Ed.). Upper Sadlle River: Prentice Hall.

Härdle, W., \& Simar, L. (2003). Applied Multivariate Statistical Analysis. Berlin: Springer Verlag.

Hodge, K., \& Petlichkoff, L. (2000). Goal profiles in sport motivation: A cluster analysis. Journal of Sport and Exercise Psychology, 22, 256-272.

Judd, C. M., \& McClelland, C. H. (1989). Data analysis: A model-comparison approach. Orlando: Harcourt Brace Jovanovitch.

Jussim, L., \& Eccles, J. S. (1992). Teacher expectations 2: Construction and reflection of student achievement. Journal of Personality and Social Psychology, 63, 947-961. 
Jussim, L. J., \& Eccles, J. (1995). Are teacher expectations biased by students' gender, social class, or ethnicity? In Y. T. Lee, L. J. Jussim \& C. R. McCauley, (Eds.), Stereotype accuracy: Toward appreciating group differences (pp. 245-271). Washington: American Psychological Association.

Lepper, M. R., \& Henderlong, J. (2000). Turning "play" into "work" and "work" into "play": 25 years of research on intrinsic versus extrinsic motivation. In C. Sansone \& J. M. Harackiewicz (Eds.), Intrinsic and extrinsic motivation: The search for optimal motivation and performance (pp. 257-307). San Diego: Academic Press.

Levesque, C., Zuehlke, N., Stanek, L., \& Ryan, R. (2004). Autonomy and competence in German and American university students: A comparative study based on selfdetermination Theory. Journal of Educational Psychology, 96, 68-84.

Li, F. (1999). The exercise motivation scale: Its multifaceted structure and construct validity. Journal of Applied Sport Psychology, 11, 97-115.

Marshall, S. J., Biddle, S. J. H., Sallis, J. F., McKenzie, T. L., \& Conway, T. L. (2002). Clustering of sedentary behaviors: and physical activity among youth: A crossnational study. Pediatric Exercise Sciences, 14, 401-417.

McNeill, M. C., \& Wang, C. K. (2005). Psychological profiles of elite school sports players in Singapore. Psychology of Sport and Exercise, 6, 117-128.

Meece, J.L., \& Holt, K. (1993). A pattern analysis of students' achievement goals. Journal of Educational Psychology, 85, 582-590.

Miserandino, M. (1996). Children who do well at school: Individual differences in perceived competence and autonomy in above-average children. Journal of Educational Psychology, 88, 203-214.

Mosteller, F., \& Tukey, J. W. (1977). Data analyses and regression: A second course in statistics. Reading: Addison-Wesley. 
Ntoumanis, N. (2001). A self-determination approach to the understanding of motivation in physical education. British Journal of Educational Psychology, 71, 225-242.

Ntoumanis, N. (2002). Motivational clusters in a sample of British physical education classes. Psychology of Sport and Exercise, 3, 177-194.

Otis, N., Grouzet, F. M. E., \& Pelletier, L. G. (2005). The latent motivational change in academic setting: a three-year longitudinal study. Journal of Educational Psychology, 97, 170-183.

Pelletier, L. G., Dion, S. Tuson, K., \& Green-Demers, I. (1999). Why do people fail to adopt environmental protective behaviors? Toward a taxonomy of environmental amotivation. Journal of Applied Social Psychology, 29, 2481-2504.

Pelletier, L., Fortier, M., Vallerand, R., \& Brière, N. (2001). Associations among perceived autonomy support, forms of self-regulation, and persistence: a prospective study. Motivation and Emotion, 25, 279-306.

Pelletier, L. G., Fortier, M. S., Vallerand, R. J., Tuson, K. M., Brière, N. M., \& Blais, M. R. (1995). Toward a new measure of intrinsic motivation, extrinsic motivation, and amotivation in sports : The Sports Motivation Scale (SMS). Journal of Sport and Exercise Psychology, 17, 35-53.

Ratelle, C. F., Guay, F., Larose, S., \& Senécal, C. (2004). Family correlates of trajectories of academic motivation during a school transition: A semi parametric group-based approach. Journal of Educational Psychology, 96, 743-754.

Reeve, J. (2002). Self-determination theory applied to educational settings. In E. Deci \& R. Ryan (Eds.), Handbook of Self-determination research (pp. 183-203). Rochester: The University of Rochester Press. 
Ryan, R. M., \& Connell, J. P. (1989). Perceived locus of causality and internalization: Examining reasons for acting in two domains. Journal of Personality and Social Psychology, 57, 749-761.

Ryan, R. M., \& Deci, E. L. (2000). Self-determination theory and the facilitation of intrinsic motivation, social development and well-being. American Psychologist, 55, 68-78.

Ryan, R. M., \& Deci, E. L. (2002). On assimilating identities to the self: A selfdetermination perspective on integration and integrity with cultures. In M. R. Leary \& J. P. Tangney (Eds.), Handbook of self and identity (pp. 253-272). New York: The Guilford Press.

Sansone, C., \& Harackiewicz, J. (2000). Controversies and new directions - is it déjà vu all over again? In C. Sansone \& J. Harackiewicz (Eds.) Intrinsic and extrinsic motivation. The search for optimal motivation and performance (pp. 443-453). San Diego: Academic Press.

Sarrazin, P., Vallerand, R., Guillet, E., Pelletier, L., \& Cury, F. (2002). Motivation and dropout in female handballers: A 21-month prospective study. European Journal of Social Psychology, 32, 395-418.

Standage, M., Duda, J., \& Ntoumanis, N. (2003). A model of contextual motivation in physical education: Using constructs from self-determination and achievement goal theories to predict physical activity intentions. Journal of Educational Psychology, 95, 97-110.

Standage, M., Duda, J., \& Ntoumanis, N. (2005). A test of self-determination theory in school physical education. British Journal of Educational Psychology, 75, 411-433.

Standage, M., Duda, J., \& Ntoumanis, N. (2006). Students' motivational processes and their relationship to teacher rating in school physical education : A self-determination theory approach. Research Quarterly for Exercise and Sport, 77, 100-110. 
Trouilloud D., Sarrazin P., Martinek T., \& Guillet E. (2002). The influence of teacher expectations on students achievement in physical education classes : Pygmalion revisited. European Journal of Social Psychology, 32, 591-607.

Vallerand, R. J. (1997). Toward a hierarchical model of intrinsic and extrinsic motivation. In M. P. Zanna (Ed.), Advances in experimental Social Psychology (pp. 271-360). New York: Academic Press

Vallerand, R. J., \& Bissonette, R. (1992). Intrinsic, extrinsic and amotivational styles as predictors of behavior : A prospective study. Journal of Personality, 60, 599-620.

Vallerand, R. J., Blais, M., Brière, N., \& Pelletier, L. G. (1989). Construction et validation de l'échelle de motivation en éducation (EME). Revue Canadienne des Sciences du Comportement, 21, 323-349.

Vallerand, R. J., \& Fortier, M. N. (1998). Measures of intrinsic and extrinsic motivation in sport and physical activity : A review and critique. In J. L. Duda (Ed.), Advances in Sport and Exercise Psychology Measurement (pp. 81-101). Morgantown: Fitness Information Technology.

Vallerand, R. J., Fortier, M. N, \& Guay, F. (1997). Self-determination and persistence in a real-life setting: Toward a motivational model of high school dropout. Journal of Personality and Social Psychology, 72, 1161-1176.

Vallerand, R. J., Pelletier, L. G., Blais, M. R., Brière, N. M., Sénécal, C., \& Vallières, E. F. (1993). On the assessment of intrinsic, extrinsic, and amotivation in education : Evidence on the concurrent and construct validity of the academic motivation scale. Educational and Psychological Measurement, 53, 159-172.

Vansteenkiste, M. Simons, J., Lens, W., Sheldon, K., \& Deci, E. (2004). Motivating learning, performance, and persistence: The synergistic effects of intrinsic goal 
contents and autonomy-supportive contexts. Journal of Personality and Social Psychology, 87, 246-260.

Vlachopoulos, S. P., Karageorghis, C. I., \& Terry, P. C. (2000). Motivation profiles in sport: A self-determination theory perspective. Research Quarterly for Exercise and Sport, 7, 387-397.

Wang, J. C. K., \& Biddle, S. J. H. (2001). Young people motivation profiles in physical activity: A cluster analysis. Journal of Sport and Exercise Psychology, 23, 1-22.

Wang, J. C. K., Chatzisarantis, N. L. D., Spray, C. M., \& Biddle, S. J. H. (2002). Achievement goal profiles in school physical education: Differences in selfdetermination, sport ability beliefs, and physical activity. British Journal of Educational Psychology, 72, 433-445.

Weiner, B. (1979). A theory of motivation for some classroom experience. Journal of Educational Psychology, 71, 3-25. 


\section{Footnotes}

${ }^{1}$ In France, high school is comprised of junior high school, which usually includes students that are 11 to 15 years old, between $6^{\text {th }}$ and $9^{\text {th }}$ grades, and senior high school, which includes older students, between $10^{\text {th }}$ and $12^{\text {th }}$ grade. Both of our sample consisted of junior high school students (i.e., the 4 first grades of high school)

${ }^{2}$ Few authors (e.g., Cokley et al., 2001; Fairchild et al., 2005) questioned the distinctiveness of IM toward Knowledge and Accomplishment sub-scales, insofar as they appeared very correlated $(>.86)$. Results in a pilot study we carried out with a representative sample of 100 students, showed that scores on IM toward Knowledge and Accomplishment were very correlated $(\phi=.92)$. A test of the discriminant validity between the two constructs consisting in examining whether the pair of latent factors could be treated as a single construct by setting each correlation to 1.0 and comparing the constrained model to a model in which the correlation was free to vary revealed that correlation was not significantly different from 1.0 thereby did not supporting the discriminant validity of the constructs. Finally, interviews carried out with 10 pupils of this sample showed they did not perceived the nuances which could exist between items assessing IM toward Knowledge (e.g., "For the pleasure I experience when I learn new skills") and those assessing IM toward Accomplishment (e.g., "For the pleasure I experience when I improve some of my weaknesses"). As a result, only 3 items among the most representative of those sub-scales have been retained in this study. ${ }^{3}$ Chi-squared tests of association were conducted in both studies to examine the possible link between cluster membership and gender or school year. The analyses revealed no association between students' gender and cluster membership. On the other hand, school year tended to be related to cluster membership in Study 1 (students from $6^{\text {th }}$ grade being slightly over-represented in the self-determined cluster, and under-represented in the non self-determined cluster; an opposite pattern was observed for students from $9^{\text {th }}$ grade), and 
was significantly related to cluster membership in Study 2 (students from $8^{\text {th }}$ grade being slightly over-represented in the moderate cluster, and under-represented in the other clusters). Theses results are coherent with past literature in education that indicate a decrease of self-determined motivation as age increases (Otis, Grouzet, \& Pelletier, 2006; Ratelle, Guay, Larose, \& Senécal, 2004).

${ }^{4}$ An additional 3 (profile) $\times 3$ (grade) ANOVA has been conducted. It revealed (1) a significant effect of grade $(p<.05)$, the performance tended to be higher with the grade level, (2) a significant effect of the motivational profile $(p<.01)$, with a significant difference between the 3 profiles $(p<.05)$, and (3) no interaction effect $(p=.28)$.

${ }^{5}$ When a contrast shows a significant link with an outcome, it means that the two profiles differ significantly on this variable. If both of the contrasts show significant links, then the three profiles are distinct from each other, because if self-determined $\neq$ moderate, and moderate $\neq$ self-determined, then non-self-determined $\neq$ self-determined.

${ }^{6}$ An additional model in which students' age was used as covariant revealed the same pattern of results and no significant association between this variable and the three objective criteria of students' achievement $(\beta=.01, \mathrm{p}>.89 ; \beta=-.06, \mathrm{p}>.25 ; \beta=-.01, \mathrm{p}>.88$, for effort, final performance and final grade, respectively). 
Table 1

Items of the motivation scale with corresponding factor loadings (Study 1)

"I participate in gymnastics classes..."

Items

Loadings

IM toward Stimulation

For the excitement I feel when I am really involved in the activity $\quad .82$

Because this activity is fun $\quad .93$

For the emotions I experience while I practice this activity $\quad .87$

IM toward Knowledge or Accomplishment

For the pleasure I experience when I improve some of my weaknesses $\quad .75$

For the pleasure I experience when I learn new skills $\quad .88$

For the satisfaction I experience while I am perfecting my abilities .91

Identified Regulation

Because what I learn in this activity will be useful later $\quad .80$

Because it is important and it can help me for other things $\quad .88$

Because this activity is important for my personal growth $\quad .71$

Introjected Regulation

Because I absolutely need to succeed in this activity $\quad .77$

Because I would feel bad about myself if I did not $\quad .78$

Because I would feel guilty if I could not succeed in this activity .62

External Regulation

Because I don't want to disappoint important people 37

Because I'll get into trouble if I don't do what the teacher's asking $\quad .56$

Because that's what I'm supposed to do $\quad .72$

Amotivation

I don't know why I go in gymnastics, if I could, I would get exempted $\quad .69$

But it doesn't worth it, I feel that I'm wasting my time $\quad .74$

$\begin{array}{ll}\text { I don't see why we should have gymnastics } & .77\end{array}$

Note: This Table presents an English translation of the French items used in the studies. 
Table 2

Descriptive statistics and correlations between the variables (Study 1).

\begin{tabular}{|c|c|c|c|c|c|c|c|c|c|c|}
\hline & & M & $S D$ & $\alpha$ & 2 & 3 & 4 & 5 & 6 & 7 \\
\hline 1 & IM toward stimulation & 3.56 & 1.99 & .90 & $.65 * * *$ & $63 * * *$ & $.52 * * *$ & $-.32 * * *$ & $-.52 * * *$ & $.26 * * *$ \\
\hline 2 & IM toward Knowledge and Accomplishment & 4.15 & 1.92 & .88 & & $.75 * * *$ & $.62 * * *$ & $-.28 * * *$ & $-.53 * * *$ & $.17 *$ \\
\hline 3 & Identified Regulation & 3.29 & 1.80 & .84 & & & $.59 * * *$ & $-.19 * *$ & $-.50 * * *$ & $.13^{t}$ \\
\hline 4 & Introjected Regulation & 3.24 & 1.60 & .69 & & & & -.02 & $-.25 * * *$ & .01 \\
\hline & External Regulation & 3.51 & 1.71 & .67 & & & & & $.57 * * *$ & $-.14 *$ \\
\hline & Amotivation & 3.28 & 1.95 & .78 & & & & & & $-.37 * * *$ \\
\hline & Final performance in Gymnastics & 4.14 & 1.70 & .93 & & & & & & \\
\hline
\end{tabular}

Note. ${ }^{* * *} p<.001,{ }^{* *} p<.01,{ }^{*} p<.05,{ }^{t} p<.07$ 
Table 3

Descriptive statistics for the three clusters -Study I

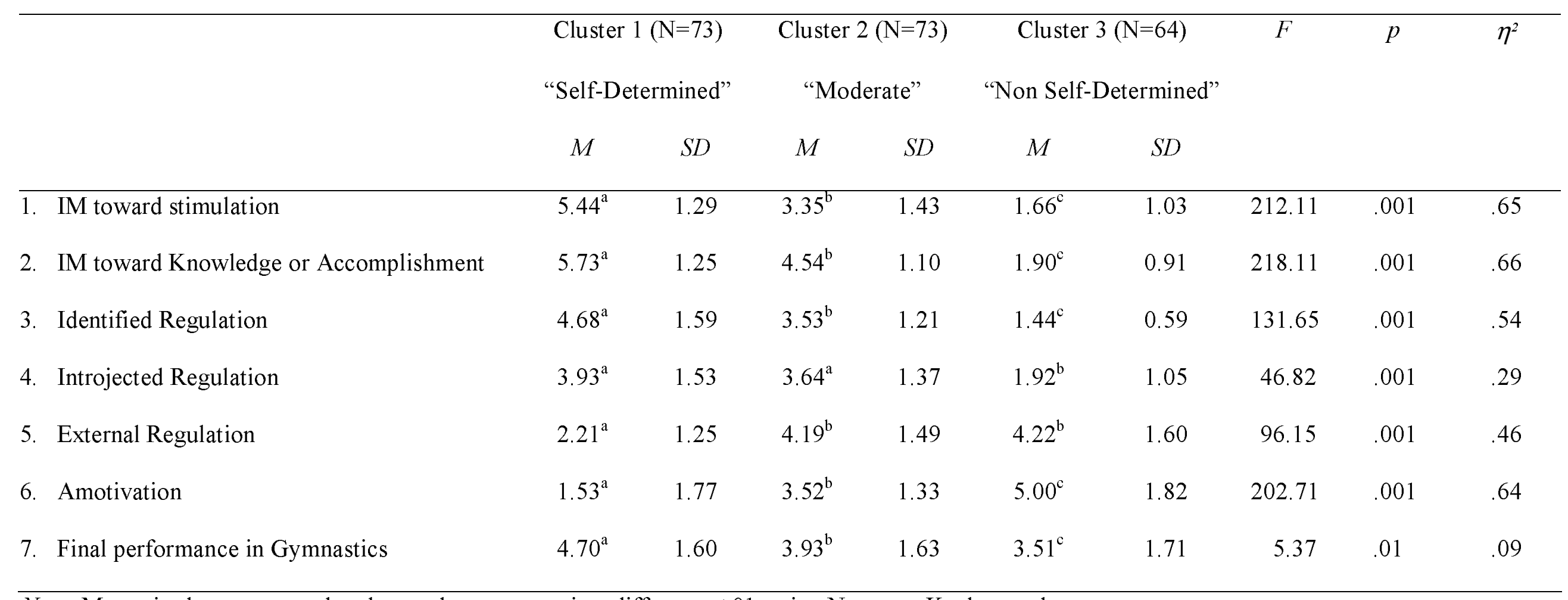

Note. Means in the same row that do not share superscripts differ at $p<.01$, using Newman-Keuls post-hoc tests. 
Table 4

Descriptive statistics for the three clusters - Study 2

\begin{tabular}{|c|c|c|c|c|c|c|c|c|c|c|}
\hline & & \multirow{3}{*}{$M$} & \multirow{3}{*}{$S D$} & \multirow{3}{*}{$\alpha$} & \multicolumn{2}{|c|}{ Cluster $1(\mathrm{~N}=84)$} & \multicolumn{2}{|c|}{ Cluster $2(\mathrm{~N}=91)$} & \multicolumn{2}{|c|}{ Cluster $3(\mathrm{~N}=40)$} \\
\hline & & & & & \multicolumn{2}{|c|}{ "Self-Determined" } & \multicolumn{2}{|c|}{ "Moderate" } & \multicolumn{2}{|c|}{ "Non Self-Determined" } \\
\hline & & & & & $M$ & $S D$ & $M$ & $S D$ & $M$ & $S D$ \\
\hline & IM toward stimulation & 3.56 & 1.99 & .88 & 5.67 & 1.03 & 3.09 & 1.11 & 1.71 & 0.80 \\
\hline 2. & IM toward Knowledge or Accomplishment & 4.15 & 1.92 & .84 & 5.65 & 1.14 & 3.98 & 1.13 & 1.94 & 0.90 \\
\hline 3. & Identified Regulation & 3.29 & 1.80 & .80 & 5.13 & 1.29 & 3.22 & 1.07 & 2.06 & 1.08 \\
\hline & Introjected Regulation & 3.24 & 1.60 & .67 & 4.23 & 1.39 & 3.39 & 1.20 & 1.90 & 0.92 \\
\hline 5 . & External Regulation & 3.51 & 1.71 & .72 & 2.05 & 1.40 & 2.83 & 1.39 & 5.11 & 1.35 \\
\hline & Amotivation & 3.28 & 1.95 & .88 & 1.77 & 1.30 & 2.80 & 1.31 & 5.94 & 1.14 \\
\hline & Provided effort & 4.35 & 3.43 & - & 4.72 & 2.68 & 4.46 & 3.60 & 3.17 & 2.54 \\
\hline & Initial performance in Gymnastics & 3.32 & 1.10 & .91 & 3.68 & 1.08 & 3.22 & 1.12 & 2.76 & 1.41 \\
\hline & Final performance in Gymnastics & 4.65 & 1.48 & .92 & 5.25 & 1.40 & 4.49 & 1.42 & 3.68 & 1.58 \\
\hline & Grade & 12.62 & 3.65 & - & 14 & 3.47 & 12.44 & 3.39 & 9.91 & 4.05 \\
\hline
\end{tabular}




\section{Figure Captions}

Figure 1: Motivational profiles in Study 1

Figure 2: Hypothesized model of achievement

Figure 3: Motivational profiles in Study 2

Figure 4: Path analysis contrasting the self-determined, moderate and non self-determined profiles (All paths are significant at $p<.05$ except when it is specified by $n s$ ) 


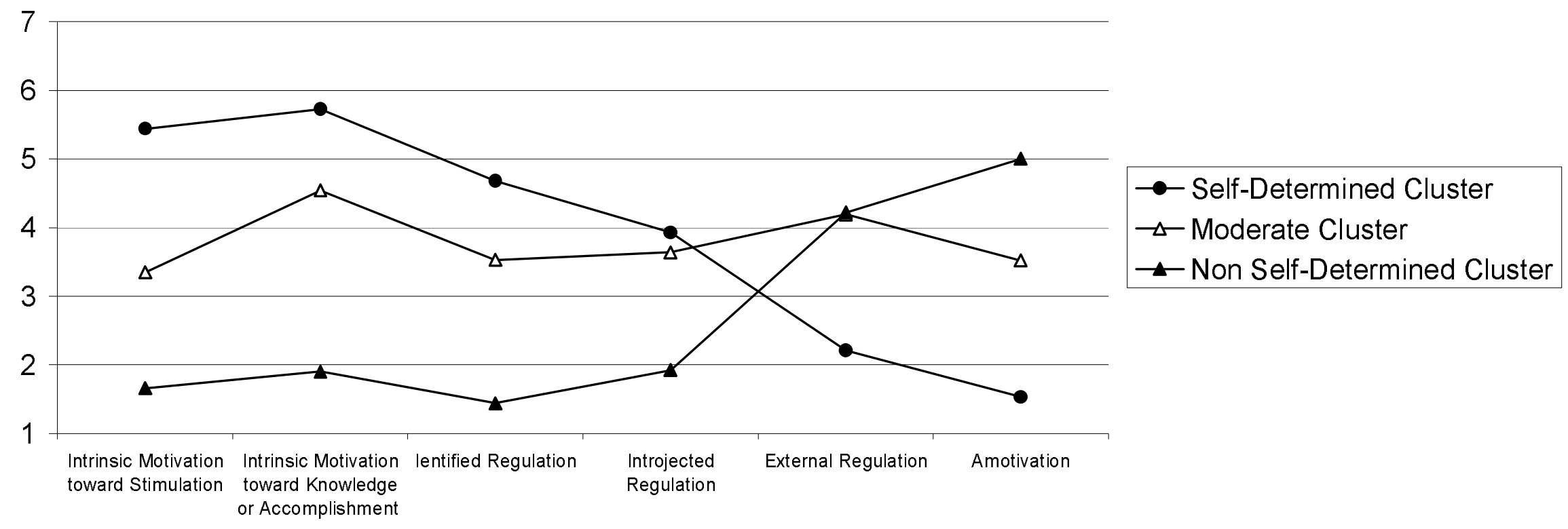




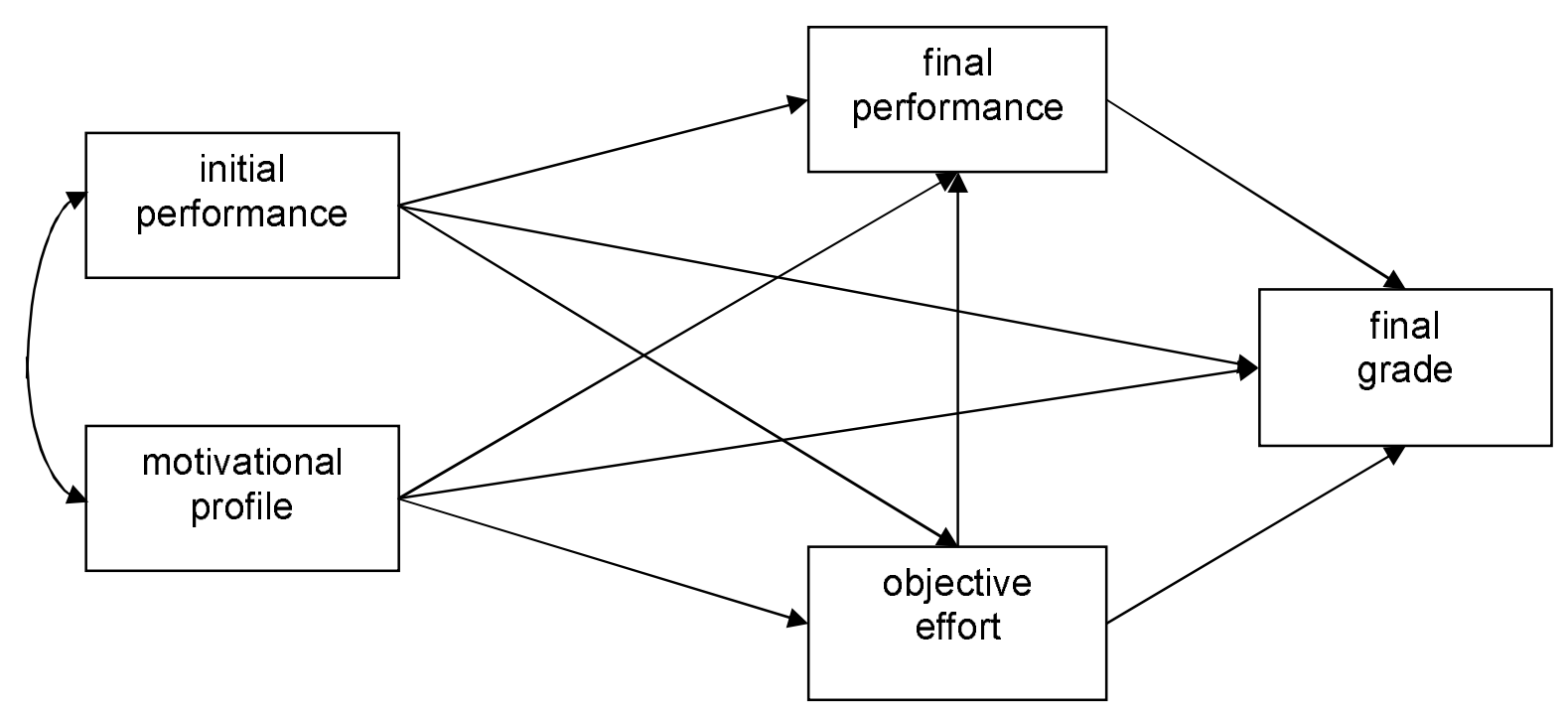




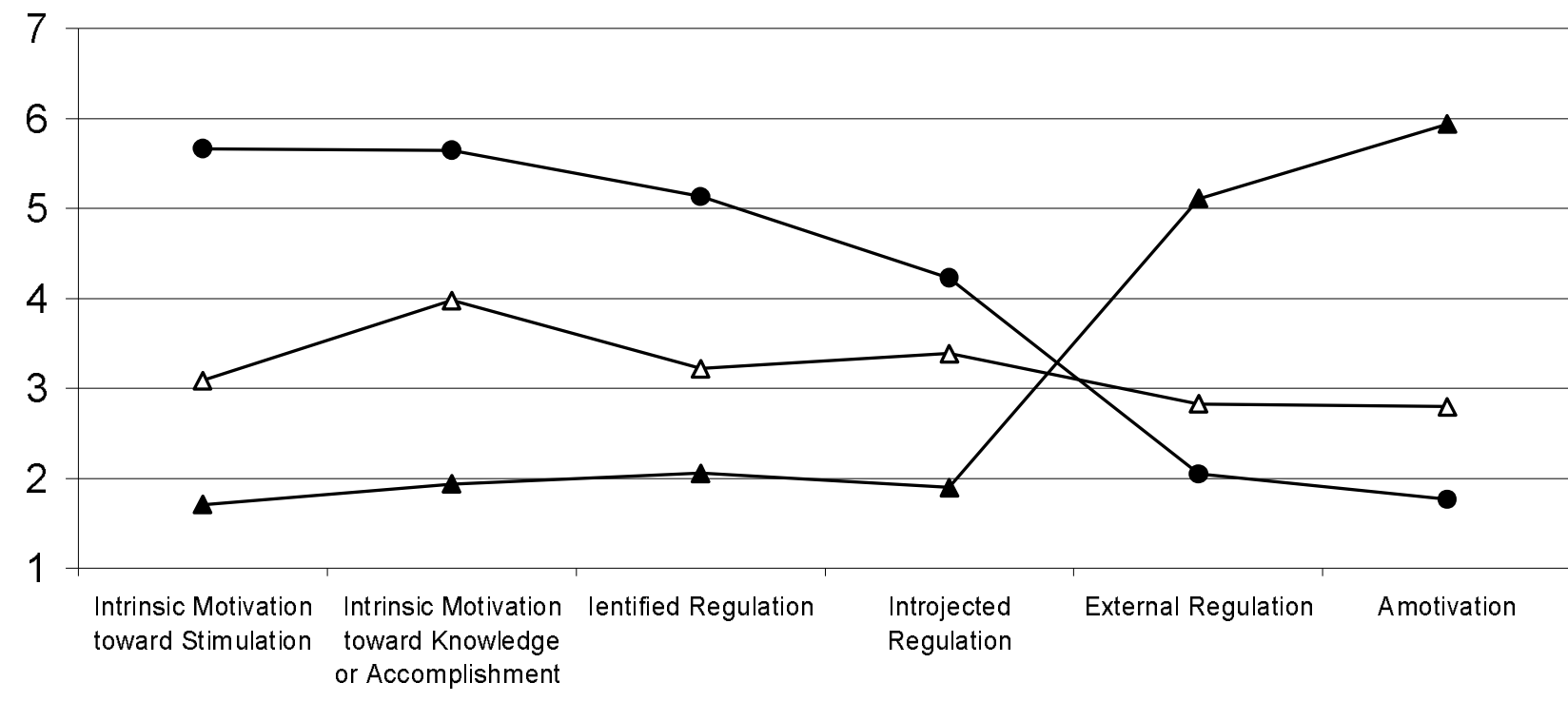

$\bullet-$ Self-Determined Cluster $\triangle-$ Moderate Cluster

$\neg$ Non Self-Determined Cluster

Intrinsic Motivation Intrinsic Motivation lentified Regulation

Introjected

External Regulation

Amotivation 


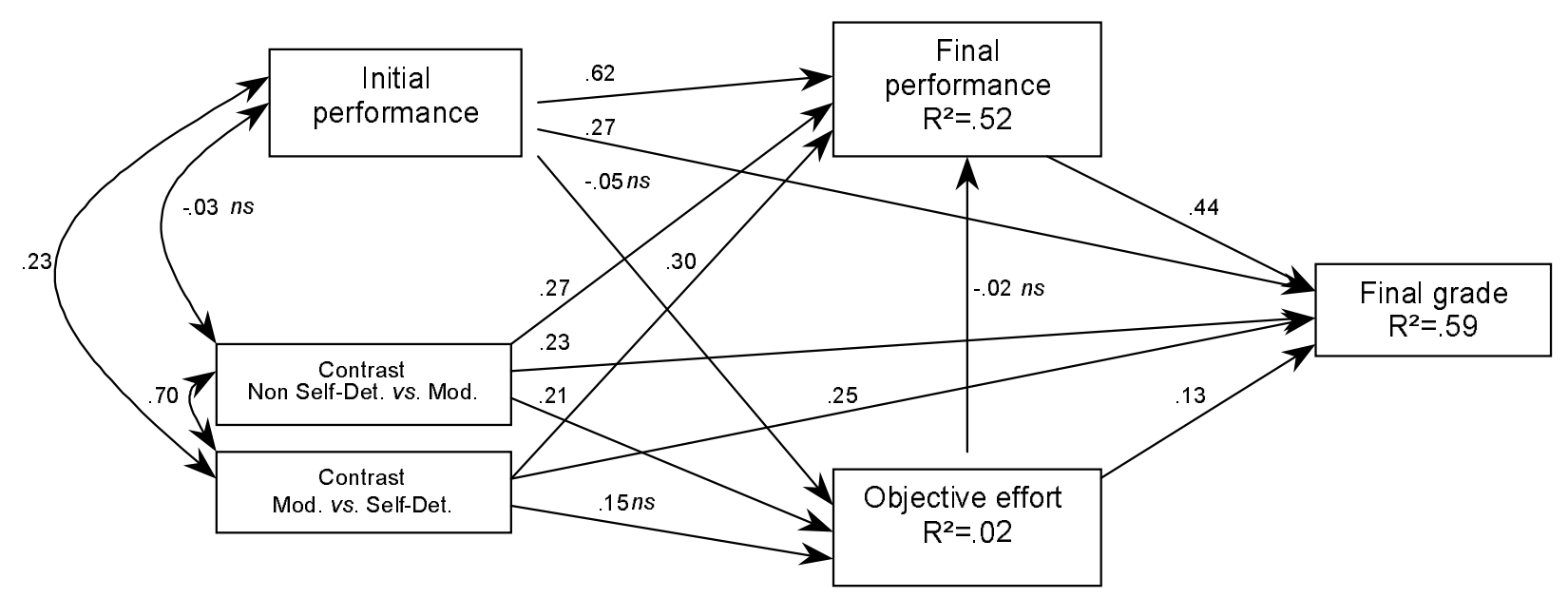

